\title{
sciendo
}

\section{Successful and Unsuccessful Offensive Sequences Ending in a Shot in Professional and Elite Under-16 Basketball}

\author{
by \\ Roberto Alsasua ${ }^{1}$, Daniel Lapresa ${ }^{1}$, Javier Arana ${ }^{1}$, M. Teresa Anguera ${ }^{2}$, \\ Belén Garzón ${ }^{1}$
}

\begin{abstract}
Following observational methodology, we analyzed successful and unsuccessful offensive attacks by professional and elite under-16 (U16) basketball players in Spain using an adapted ad hoc observation instrument designed to study efficiency in basketball. We identified both similarities and differences between how players from both categories built their attacks. The synchronic statistical analysis based on frequency counts showed that shots were more efficient in professional basketball and that U16 basketball was less static and had a higher frequency of fast breaks. Diachronic analysis, which consisted of T-pattern detection using Theme software, allowed us to identify characteristic successful and unsuccessful offensive sequences in professional and elite U16 basketball. These results have practical implications as they can be used to design training drills and prepare for competitions in U16 and professional basketball.
\end{abstract}

Key words: basketball, U16, ACB, offensive sequences, observational methodology, T-patterns.

\section{Introduction}

The vast majority of studies of efficiency in basketball use conventional statistical techniques based on game-related statistics (Ratgeber et al., 2013).

As points in basketball are scored by putting the ball through the basket, shot success is a logical measure for analyzing efficiency (Simovic et al., 2012). Technical-tactical aspects of shooting actions, however, are not easy to analyze (Podmenik et al., 2012), as they are influenced by complex, interacting factors (Courel et al., 2013; Maszczyk et al., 2014; Marmarinos et al., 2016; Ozakaki and Rodacki, 2012). Attempts have been made to break down this complexity by studying aspects of the game preceding a successful or unsuccessful shot, such as fast breaks (Refoyo et al., 2009), space-time coordination dynamics (Bourbousson et al., 2010), network metrics (Fewel et al., 2012), and interactions between attackers and defenders (García et al., 2013a).

Observational methodology (Anguera, 1979) provides an optimal framework for capturing the frequency, duration, and order of events and behaviors, producing datasets that can then be subjected to sequential and/or temporal analysis in search of patterns. Sequential and temporal analysis of sequences of play that end in a shot are particularly relevant for analyzing efficiency in basketball (Ibáñez et al., 2009; Oliver and Camerino, 2013; Sampaio et al., 2010).

Most studies of efficiency in basketball have analyzed professional or elite basketball (García et al., 2013b; Mexas et al., 2005; Sautu et al., 2009; Mikołajec et al., 2012; Strumbelj et al., 2013), but there have also been studies of youth basketball performance (Garzón et al., 2011;

\footnotetext{
1 - Department of Educational Sciences. University of La Rioja. Logroño, Spain.

2 - Faculty of Psychology. Institute of Neurosciences. University of Barcelona. Barcelona, Spain.
} 
Lorenzo et al., 2010; Ortega et al., 2007). To create a model of sporting excellence that will serve as a benchmark for developing players of all ages and for players moving from simply "performing" to "excelling" or to playing at a professional level, we need to understand and compare what happens in games played by professionals and by players still in the developing stage.

Within the broad context of analyzing some of the components necessary for this transition from development to excellence, the aim of this study was to investigate factors associated with successful and unsuccessful offensive outcomes in matches played by topranked teams in La Liga ACB (ACB), the top Spanish professional men's league, and by elite Spanish U16 teams (U16) competing at the highest level in this age category by searching for similarities and differences between them. To achieve this, we used SOBL-2, an ad hoc observation instrument designed to study efficiency in elite basketball (Fernández et al., 2009), within the framework of an observational methodology study. SOBL-2 has been used to study performance in professional competitions (Fernández et al., 2009) and youth categories (Lapresa et al., 2013, 2014), and, as illustrated in these studies, it produces data in a format that can be analyzed in search of temporal patterns. In the present study, we searched for temporal patterns (T-patterns) using Theme (v. 5.0) software (Magnusson, 1996, 2000).

\section{Methods}

We employed observational methodology (Anguera, 1979), which has proven to be a robust scientific method for analyzing complex games such as basketball (Courel et al., 2013; Garzón et al., 2011; Lapresa et al., 2013, 2014; Uchida et al., 2014).

The specific design employed was followup (inter-sessional and intra-sessional), nomothetic and multidimensional [F/N/M] (Anguera et al., 2011). The follow-up was intersessional because we studied seven U16 matches and seven ACB matches, and intra-sessional because we undertook a frame-by-frame analysis of behaviors throughout each of the matches analyzed. The study was nomothetic because we observed different members of different teams playing different matches, and multidimensional because we studied multiple dimensions of behavior. These dimensions, which correspond to the criteria in the observation instrument, included both proxemic behaviors (those related to movements in different areas of the court) and gestural behaviors (those related to different technical-tactical actions).

\section{Participants}

We studied a convenience sample of topranked ACB and U16 teams. The U16 teams had played in the final phases (quarterfinals, semifinals, and finals) of the 2012 Male U16 Spanish Club Championship and the ACB teams had played in the final phases of the 2012 Copa del Rey, which is a cup competition disputed by the top seven teams in the ACB halfway through the season and the host team.

The research project was approved by the scientific committee of the University of La Rioja and was in accordance with the Ethical Principles of Psychologists, the Code of Conduct of the American Psychological Association, and the guidelines of the Ethics Committee of the Spanish Association of Psychologists.

\section{Observation instrument}

The SOBL-2 is an ad hoc observation instrument designed by Fernández et al. (2009) to study efficiency in elite basketball. The original instrument was adapted minimally for the purpose of this study. The instrument combines a field format and five systems of categories. The field format consists of five dimensions that are each broken down into a system of categories (Amatria et al., 2016). The instrument is shown in Table 1.

\section{Procedures}

Video footage from the fourteen U16 and ACB matches analyzed was used to record and code data for the teams that won the quarterfinals (four datasets), the semifinals (two datasets), and the final (one dataset) in each competition. Seven datasets were thus generated for each category. The resulting datasets contained 524 offensive sequences that ended in a shot in the U16 category and 456 in the ACB category.

To code the data, the observation instrument was loaded into Match Vision Studio (v. 3) software (Castellano et al., 2008). For each offensive sequence, the observers coded a minimum of two and a maximum of six actions immediately preceding a shot or completion (e.g., 
foul committed/received). The order of actions was denoted as -1 for the last action before the shot/completion, -2 for the $2^{\text {nd }}$ action before the shoot/completion, -3 for the $3^{\text {rd }}$ action before the shoot/completion, and so on. The side and area of the court where each action occurred were also recorded. According to Bakeman (1978), the data produced corresponded to type IV, concurrent, time-based data, illustrating the informative potential of the subsequent T-patterns detected.

Data quality control: agreement between observations and generalizability of results Inter-observer agreement

Inter-observer agreement was calculated quantitatively using Cohen's kappa statistic (1968). This analysis was performed using GSEQ5 (v. 5.1) software following the recommendations of Bakeman and Quera (2001) and consisted of comparing the data coded by two observers for each set of data (match/team observed). A kappa statistic of over 0.81 was obtained for all the datasets (Table 2), attesting to the reliability of the data subsequently analyzed.

\section{Generalizability of results}

To estimate the extent to which our results could be generalized to other situations, we performed a generalizability $(G)$ analysis within the framework of $G$ Theory (Cronbach et al., 1972). The analysis, conducted with SAGT (v. 1.0) software (Hernández-Mendo et al., 2012), consisted of estimating the $\mathrm{G}$ coefficients for the general linear model corresponding to the design "categories/matches", where matches were the instrumentation facet.

In the ACB category, $96.1 \%$ of the variability was accounted for by the categories facet, $0.4 \%$ by the matches facet, and $3.4 \%$ by the interaction between these facets. For the U16 category, the corresponding rates were $93 \%, 1.4 \%$, and $5.7 \%$. The $\mathrm{G}$ coefficient for both categories was high $\left(\mathrm{e}^{2}=0.995\right.$ for $\mathrm{ACB}$ and $\mathrm{e}^{2}=0.991$ for $\mathrm{U16)}$, indicating the homogeneity of the data corresponding to the matches/team observed and illustrating the adequacy of the convenience sample used in this study.

\section{Data analysis}

We performed two types of data analyses: one to investigate relationships between categorical variables and another to search for hidden T-patterns within the data. The respective analyses were performed using SPSS (v. 19.0) and
Theme (v. 5.0) softwares (Magnusson, 2000).

Relationships between categorical variables were investigated using contingency tables and Pearson's $\chi^{2}$. This statistic provides a measure of the degree of dependence or independence between two nominal variables.

All seven datasets for each category were combined for the respective T-pattern analyses. The algorithm in Theme (v. 5.0) searches for free heuristic-type critical interval relationships, i.e., it starts from the extreme with the lowest $p$ value (with significance set at $p<0.005$ in our case). To ensure that the T-patterns detected were not the result of chance, we applied a simulation filter that performed 2000 randomizations $(1 / 0.005$ [level of significance] $x$ 10) for each critical interval relationship before it was accepted. Tpatterns were accepted thus if Theme found, among all the randomly generated relationships, $(n / 2000)<0.005$ critical interval relationships with internal intervals of the same size as or smaller than those of the relationship being tested. A minimum frequency of three occurrences was set for each T-pattern.

\section{Results}

\section{Associations between categorical variables}

The following actions in sequences leading up to a shot were significantly more common in ACB than in U16: action $-2\left(\chi^{2}=5.296\right.$; $p=0.021)$, action $-3\left(\chi^{2}=4.319 ; p=0.038\right)$, and action $-4\left(\chi^{2}=5.528 ; p=0.019\right)$. Specifically, ACB had a higher number of receptions for action $-1\left(\chi^{2}\right.$ $=4.397 ; p=0.036)$ and action $-3\left(\chi^{2}=4.462 ; p=\right.$ $0.035)$ and a higher number of passes for action -2 $\left(\chi^{2}=4.530 ; p=0.033\right)$ and action $-4\left(\chi^{2}=5.528 ; p=\right.$ $0.019)$; use of the offensive area was also more common in ACB for action $-1\left(\chi^{2}=6.013 ; p=\right.$ $0.014)$, action $-2\left(\chi^{2}=14.427 ; p \leq 0.001\right)$, action -3 $\left(\chi^{2}=10.493 ; p=0.001\right)$, and action $-4\left(\chi^{2}=14.853 ; p\right.$ $\leq 0.001)$.

Regarding differences in the use of sides and areas of the court for actions preceding a shot, the following were all significantly more common in U16: use of the defensive key for action $-1\left(\chi^{2}=\right.$ 10.314; $p=0.037)$ and action $-2\left(\chi^{2}=4.280 ; p=\right.$ $0.039)$; use of the right defensive side $\left(\chi^{2}=5.419 ; p\right.$ $=0.020)$ and the right defensive baseline area for action $-2\left(\chi^{2}=6.694 ; p=0.010\right)$; and use of the left defensive side $\left(\chi^{2}=4.355 ; p=0.044\right)$, the left defensive baseline area $\left(\chi^{2}=5.253 ; p=0.022\right)$, the 
right defensive side $\left(\chi^{2}=4.355 ; p=0.037\right)$, and the outer defensive area $\left(\chi^{2}=8.757 ; p=0.003\right)$ for action -4 . The following, by contrast, were more common in ACB: use of the outer offensive area $\left(\chi^{2}=4.334 ; p=0.037\right)$ for action -1 ; the central offensive area $\left(\chi^{2}=11.116 ; p=0.001\right)$ and the intermediate offensive area $\left(\chi^{2}=10.024 ; p=0.002\right)$ for action -2; and the central offensive area $\left(\chi^{2}=\right.$ $16.227 ; p \leq 0.001)$ and the outer offensive area $\left(\chi^{2}=\right.$ 13.876; $p \leq 0.001$ ) for action -4 .

To compare the frequency of efficient and inefficient actions in the completion of a sequence (completion dimension) between ACB and U16, we built contingency tables summarizing the frequency of these actions considered both individually and grouped by successful (favorable) actions (basket, foul received, basket and free shot) and unsuccessful (unfavorable) actions (missed basket, violation/foul in attack, block). We also compared frequency of actions according to where they occurred. The only significant difference observed was that shots ending in a basket were significantly more common in ACB $\left(\chi^{2}=4.060 ; p=0.044\right)$.

We replicated the above analysis for $\mathrm{ACB}$ and U16 separately to investigate which completion actions were more frequently associated with a successful or unsuccessful outcome in each category. In the case of both ACB and U16, successful outcomes were significantly more common in the offensive key $\left(\chi^{2}=24.425 ; p \leq\right.$ 0.001 for U16 and $\chi^{2}=25.160 ; p \leq 0.001$ for ACB). Specifically, baskets scored were also more common in this area for both categories $\left(\chi^{2}=\right.$ $7.925 ; p=0.005$ for $\mathrm{U} 16$ and $\chi^{2}=6.723 ; p=0.010$ for $\mathrm{ACB})$. With regard to the side of the court used, missed baskets were significantly less common in both $\mathrm{U} 16$ and $\mathrm{ACB}$ in the right offensive baseline area $\left(\chi^{2}=7.890 ; p=0.005\right.$ for $\mathrm{U} 16$ and $\chi^{2}=6.985$; $p=0.008$ for ACB) and the left offensive baseline area $\left(\chi^{2}=4.044 ; p=0.044\right.$ for U16 and $\chi^{2}=5.637 ; p$ $=0.018$ for $\mathrm{ACB})$.

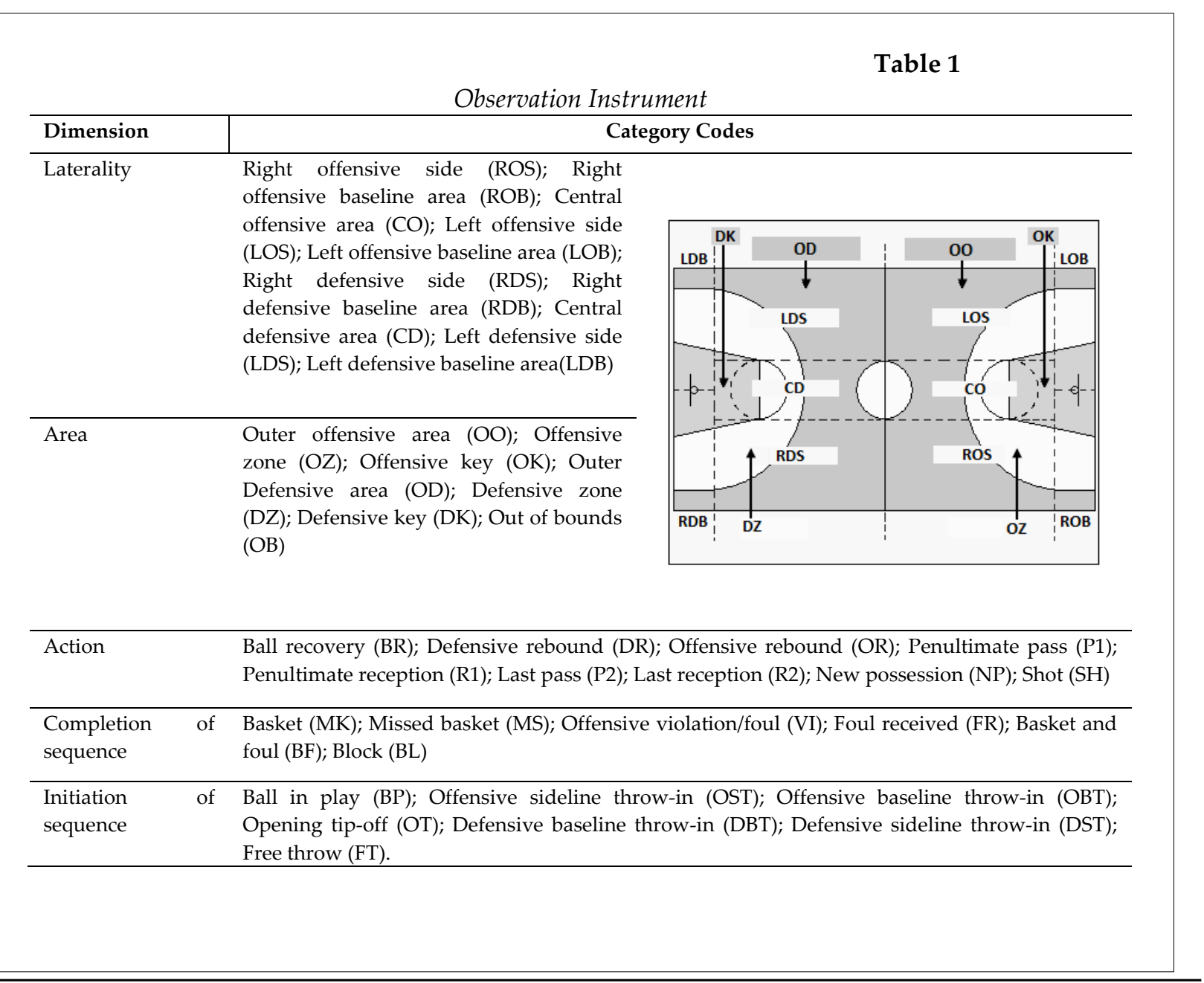


Table 2

Cohen's kappa statistic and percentage of inter-observer agreement for each dataset (match/observed team-rival team)

\begin{tabular}{llcc}
\hline Modality & Match/observed team-rival team & Kappa & \% Agreement \\
\hline \multirow{4}{*}{ ACB } & Caja Laboral-Gipuzkoa & 0.81 & $82 \%$ \\
\cline { 2 - 4 } & FC Barcelona-Lucentum & 0.82 & $83 \%$ \\
\cline { 2 - 4 } & Banca Cívica-Unicaja & 0.91 & $92 \%$ \\
\cline { 2 - 4 } & Real Madrid CF-Fuenlabrada & 0.82 & $83 \%$ \\
\cline { 2 - 4 } & FC Barcelona-Baskonia & 0.82 & $82 \%$ \\
\cline { 2 - 4 } & Real Madrid CF-Banca Cívica & 0.81 & $82 \%$ \\
\cline { 2 - 4 } & Real Madrid-FC Barcelona & 0.84 & $90 \%$ \\
\hline \multirow{5}{*}{ U16 } & FC Barcelona-Torrelodones & 0.89 & $90 \%$ \\
\cline { 2 - 4 } & Cajasol-Easo & 0.90 & $83 \%$ \\
\cline { 2 - 4 } & Peixe-Joventut & 0.81 & $80 \%$ \\
\cline { 2 - 4 } & Unicaja-Endesa & 0.83 & $83 \%$ \\
\cline { 2 - 4 } & Cajasol-FC Barcelona & 0.86 & \\
\cline { 2 - 4 } & Peixe-Unicaja & 0.89 & 80.82 \\
\cline { 2 - 4 } & Cajasol-Peixe & & \\
\hline
\end{tabular}

Table 3

Characteristic successful and unsuccessful sequences detected by T-pattern analysis for U16 and ACB

\begin{tabular}{|c|c|c|c|c|}
\hline $\begin{array}{l}\text { Sequence } \\
\text { code }\end{array}$ & Sequence & $\begin{array}{l}\text { Disci- } \\
\text { pline }\end{array}$ & Frequency & Position of shot \\
\hline Mk1 & ros,oo,r1_co,ok,p2_lob,ok,r2_lob,ok,fn,mk & U16 & 17 & $\begin{array}{c}\text { Left offensive baseline } \\
\text { area / Offensive key }\end{array}$ \\
\hline Mk2 & ros,oo,p1_los,oo,r1_los,oo,p2_lob,ok,r2_lob,ok,fn,mk & U16 & 13 & $\begin{array}{c}\text { Central offensive area / } \\
\text { Offensive key }\end{array}$ \\
\hline Mk3 & los,oo,p1_co,oo,r1_co,oo,p2_ros,oo,r2_ros,oo,fn,mk & $\mathrm{ACB}$ & 38 & $\begin{array}{l}\text { Right offensive side / } \\
\text { Outer offensive area }\end{array}$ \\
\hline $\mathrm{Mk} 4$ & rob,oz,r1_rob,oz,p2_lob,ok,r2_lob,ok,fn,mk & ACB & 10 & $\begin{array}{c}\text { Left offensive baseline } \\
\text { area / Offensive key }\end{array}$ \\
\hline Mk5 & co,oo,p1_los,oo,r1_los,oo,p2_lob,ok,fn,mk & $\begin{array}{r}\mathrm{U} 16 \\
\mathrm{ACB}\end{array}$ & $\begin{array}{l}13 \\
19 \\
\end{array}$ & $\begin{array}{c}\text { Left offensive baseline } \\
\text { area / Offensive key }\end{array}$ \\
\hline Mk6 & ros,oo,p1_co,oo,r1_co,oo,p2_lob,ok,r2_lob,ok,fn,mk & $\begin{array}{l}\mathrm{U} 16 \\
\mathrm{ACB}\end{array}$ & $\begin{array}{c}6 \\
18 \\
\end{array}$ & $\begin{array}{c}\text { Left offensive baseline } \\
\text { area / Offensive key }\end{array}$ \\
\hline Mk7 & los,oo,p1 ros,oo,r1_ros,oo,p2_rob,oo,r2_rob,oo,fn,mk & $\begin{array}{l}\mathrm{U} 16 \\
\mathrm{ACB}\end{array}$ & $\begin{array}{c}13 \\
2\end{array}$ & $\begin{array}{c}\text { Right offensive baseline } \\
\text { area / Outer offensive } \\
\text { area }\end{array}$ \\
\hline Ms1 & $\mathrm{co}, \mathrm{oz}, \mathrm{p} 2$ _ros,oo,r2_ros,oo,fn,ms & U16 & 10 & $\begin{array}{l}\text { Right offensive side / } \\
\text { Outer offensive area }\end{array}$ \\
\hline Ms2 & co,oz,p1_los,oo,r1_los,oo,p2_lob,oo,r2_lob,oo,fn,ms & U16 & 24 & $\begin{array}{c}\text { Left offensive baseline } \\
\text { area / Outer offensive } \\
\text { area }\end{array}$ \\
\hline Ms3 & los,oo,r1_co,oz,p2_lob,ok,r2_lob,ok,fn,ms & U16 & 10 & $\begin{array}{c}\text { Left offensive baseline } \\
\text { area / Offensive key }\end{array}$ \\
\hline Ms4 & los,oo,p1_co,oo,r1_co,oo,p2_ros,oo,r2_ros,oo,fn,ms & $\begin{array}{l}\mathrm{U} 16 \\
\mathrm{ACB}\end{array}$ & $\begin{array}{l}51 \\
44\end{array}$ & $\begin{array}{l}\text { Right offensive side / } \\
\text { Outer offensive area }\end{array}$ \\
\hline Ms5 & ros,oo,p1_ros,oo,r1_ros,oo,p2_ros,oo,r2_ros,oo,fn,ms & $\begin{array}{l}\mathrm{U} 16 \\
\mathrm{ACB}\end{array}$ & $\begin{array}{l}10 \\
14\end{array}$ & $\begin{array}{l}\text { Right offensive side / } \\
\text { Outer offensive area }\end{array}$ \\
\hline Ms6 & los,oo,p1_los,oo,r1_los,oo,p2_ros,oo,r2_ros,oo,fn,ms & $\begin{array}{r}\mathrm{U} 16 \\
\mathrm{ACB} \\
\end{array}$ & $\begin{array}{c}18 \\
8 \\
\end{array}$ & $\begin{array}{l}\text { Right offensive side / } \\
\text { Outer offensive area }\end{array}$ \\
\hline Ms7 & ros,oo,p1_co,oo,r1_co,oo,p2_los,oo,r2_los,oo,fn,ms & $\begin{array}{l}\mathrm{U} 16 \\
\mathrm{ACB}\end{array}$ & $\begin{array}{l}28 \\
16 \\
\end{array}$ & $\begin{array}{l}\text { Left offensive side / } \\
\text { Outer offensive area }\end{array}$ \\
\hline Ms8 & los,oo,r1_los,oo,p2_co,oo,r2_co,oo,fn,ms & $\begin{array}{l}\mathrm{U} 16 \\
\mathrm{ACB}\end{array}$ & $\begin{array}{c}12 \\
8 \\
\end{array}$ & $\begin{array}{c}\text { Central offensive area / } \\
\text { Outer offensive area }\end{array}$ \\
\hline Ms9 & ros,oo,r1_ros,oo,p2_co,oo,r2_co,oo,fn,ms & $\begin{array}{l}\mathrm{U} 16 \\
\mathrm{ACB}\end{array}$ & $\begin{array}{l}11 \\
10\end{array}$ & $\begin{array}{c}\text { Central offensive area / } \\
\text { Outer offensive area }\end{array}$ \\
\hline
\end{tabular}




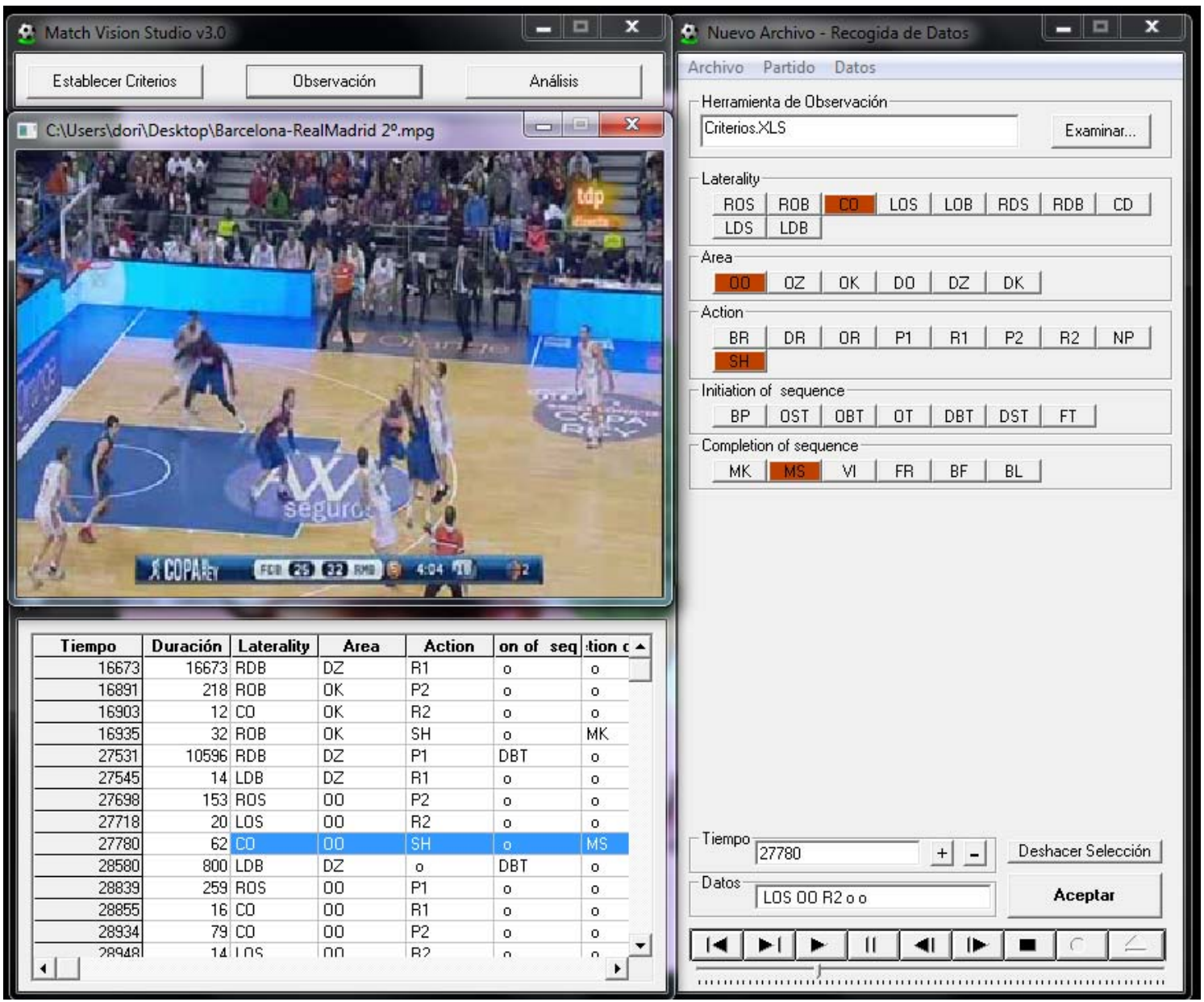

Figure 1

Screenshot showing the coding of an offensive sequence using the SOBL-2 observation instrument in Match Vision Studio. 


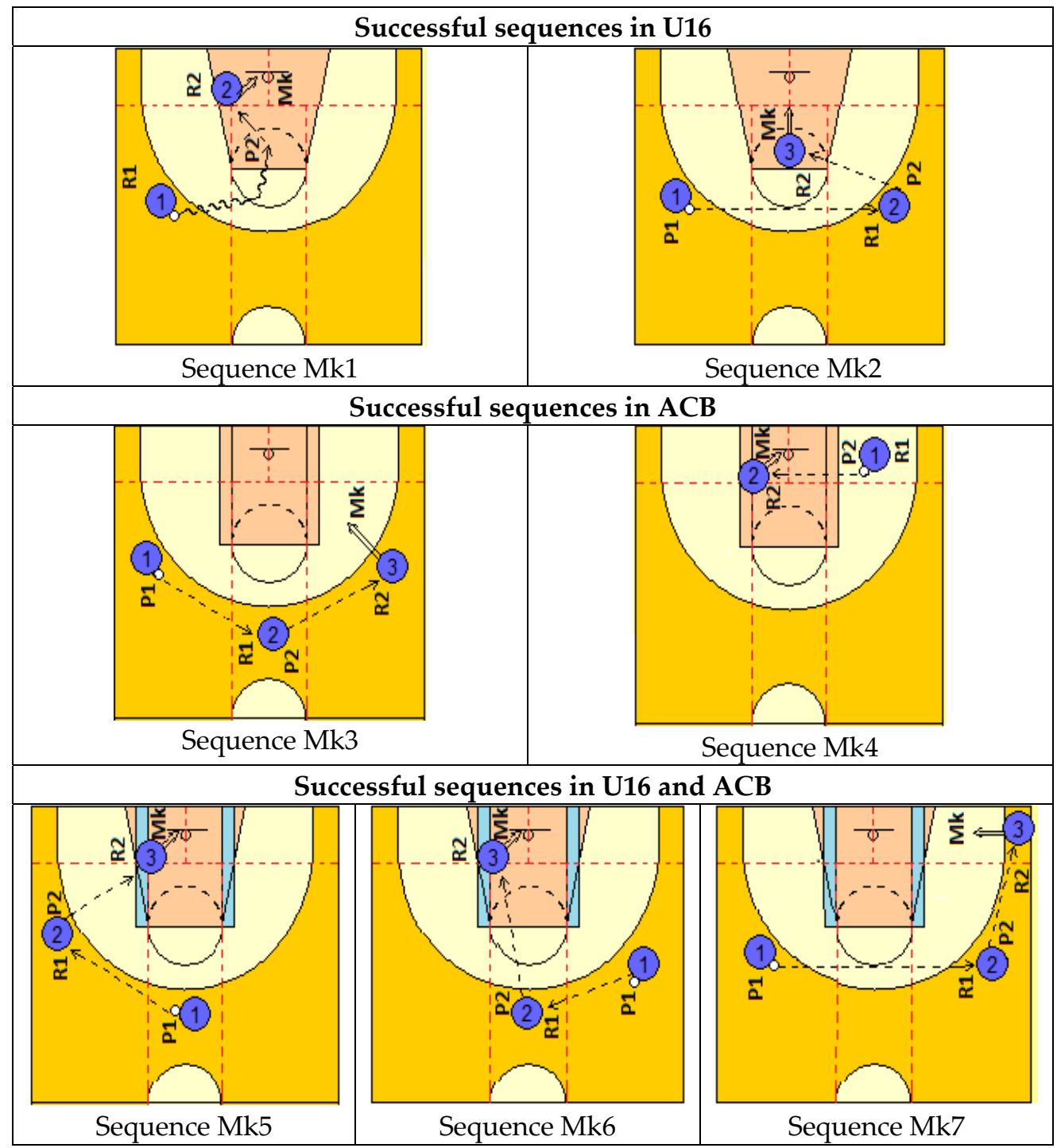

Figure 2

Efficient offensive sequences in U16 and $A C B$ 


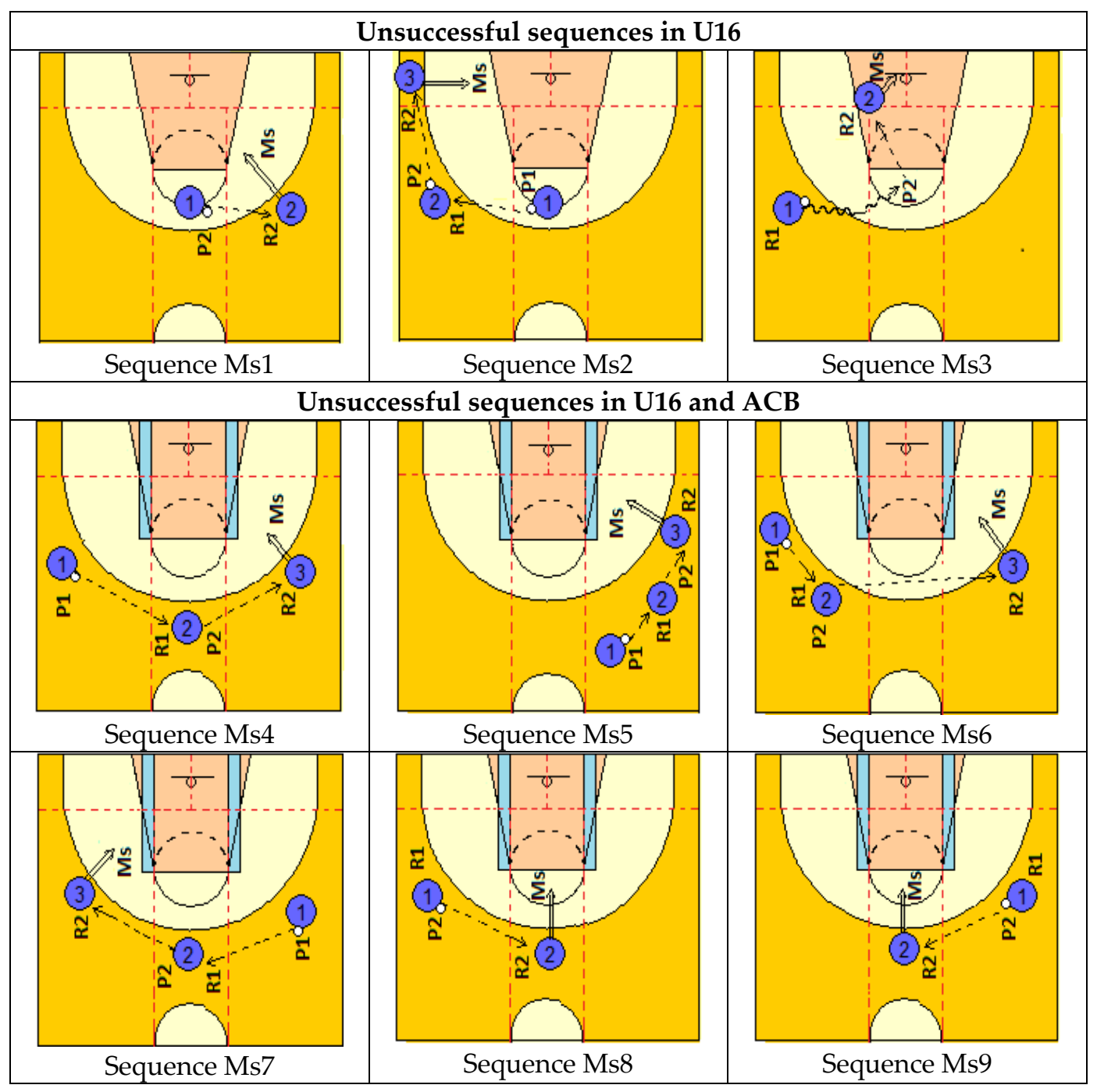

Figure 3

Inefficient offensive sequences in U16 and $A C B$ 
Unsuccessful completion actions and missed baskets were significantly more common in the outer offensive area in U16 $\left(\chi^{2}=18.555 ; p \leq\right.$ 0.001 and $\chi^{2}=7.925 ; p=0.005$, respectively). In $\mathrm{ACB}$, by contrast, they were more common in the key $\left(\chi^{2}=15.294 ; p \leq 0.001\right.$ for unsuccessful actions overall and $\chi^{2}=24.290 ; p=0.023$ for missed baskets).

On examining what happened according to the side of the court, missed baskets were more common on the right and left offensive sides $\left(\chi^{2}=\right.$ 16.193; $p \leq 0.001$ and $\chi^{2}=5.141 ; p=0.023$, respectively) in U16, while unsuccessful completion actions overall were significantly more common on the right offensive side $\left(\chi^{2}=\right.$ $7,228 ; p=0.007)$ and in the left offensive baseline area $\left(\chi^{2}=7.837 ; p=0.005\right)$.

\section{T-patterns}

Table 3 shows the T-patterns detected using the pre-established search parameters incorporating the completion multievent action. Using the information contained in the multievents that comprised the T-patterns, we identified numerous sequences that were representative of successful and unsuccessful outcomes in both ACB and U16. Each of these sequences contained distinctive technical-tactical actions (action dimension) or occurred in a different part of the court (side or area). Table 3 summarizes all the successful (En) and unsuccessful (Er) sequences that occurred at least 10 times in ACB and/or U16. To aid comprehension, we reproduced these sequences in a graph format in Figure 2 (successful sequences) and Figure 3 (unsuccessful sequences).

\section{Discussion}

Compared with elite U16 players, professional players in La Liga ACB used significantly more actions leading up to a shot. Specifically, we detected actions -1 to -4 in the defensive court; actions -1 and -2 in the key; action -2 on the right defensive side and in the right offensive baseline area; and action -4 on the left and right defensive sides and in the left defensive baseline area. Sequences consisting of one pass or no pass at all were more common in U16. These results support previous findings that youth basketball is less static than professional basketball (Fewell et al., 2012; Lorenzo et al., 2010; Ortega et al., 2007) and suggest a higher frequency of fast breaks. In a previous study of elite U14 players by our group, we found even stronger evidence that players gradually progress to a greater level of positional play as they mature professionally.

Previous studies have consistently shown that shot efficiency is greater in professional basketball (Fernández et al., 2009; Mexas et al., 2005; Ratgeber et al., 2013; Sautu et al. 2009) than in lower-level categories (Lapresa et al., 2014; Ortega et al., 2007; Piñar et al., 2014). This was confirmed in our study, as successful shots were significantly more common in ACB than in U16. The higher shooting efficiency in professional basketball has been attributed to the fact that players take their shots under less pressure from defense due to better preparation and better timing due to improved selective attention and predictive abilities (Courel et al., 2013; Ibáñez et al., 2009; Strumbelj et al., 2013). Logically, the further away a shot is taken, the less likely it is to enter the basket (Okazaki and Rodacki, 2012). This reduced accuracy was reflected in both categories in our study as the most successful shots came from areas closest to the basket: the baseline and the key.

One of the main contributions of this study is its characterization of efficient and inefficient sequences based on the T-pattern detection analysis.

Sequences Mk1 and Mk2 were found in U16 only. These consist of a shot taken from the left baseline area and the key following a pass made from the central area and the key, strategies recommended by Refoyo et al. (2009) to obtain a scoring advantage. The left baseline and the key have both been identified as effective shooting areas by Mexas et al. (2005), Fernández et al. (2009), and Lapresa et al. (2014).

Sequences Mk3 and Mk4 were found in $\mathrm{ACB}$ only. Of note in these sequences is the fact that the pass directly preceding the shot was made from adjacent areas/sides of the court, failing to create the optimal conditions (sufficient space between the passer and the receiver to destabilize the defense) described by Ortega and Gómez (2009) and Fewell et al. (2012). In sequence Mk3, this was compensated for by moving the ball around the outer area, which was used significantly more often in ACB. This outer movement of the ball has been associated with 
offensive sequences ending in a successful shot (Fernández et al., 2009; Sautu et al., 2009). In Mk3, the ball was shifted from the left to the right side of the court via the center. Central areas were used significantly more often in ACB to distribute the ball, and this strategy has been identified as effective by both Ortega and Gómez (2009) and Refoyo et al. (2009).

The following sequences were successful in both $\mathrm{ACB}$ and U16: Mk5, Mk6, and Mk7. Mk5 and Mk6 were more common in ACB and ended with a basket scored from the left baseline area and the key, respectively. In both cases, they were preceded by movement of the ball around the outer area and an inside pass. Sautu et al. (2009) and Courel et al. (2013) recommend using these two strategies in addition to switching the ball between the 2-point and 3-point areas to gain a favorable shooting occasion. Sequence Mk7 was more common in U16. It consisted of a second-last pass from the outer left to the outer right area, generating the space needed to destabilize the defence (Fewell et al., 2012; Ortega and Gómez, 2009). In this case, the shot was taken from the outer baseline area. Movement of the ball around the outside area followed by a pass creates a favorable scoring opportunity according to Sautu et al. (2009).

Our T-pattern analysis also identified a series of unsuccessful sequences, i.e., sequences that ended in a missed basket on 10 or more occasions. Ms1, Ms2, and Ms3 were observed in U16 only. Although they consisted of a final inside pass and/or a shift to outside the threepoint line (strategies recommended by Courel et al., 2013 and Sautu et al., 2009), they all involved passes in the central and intermediate areas before the shot as well as short passes that failed to open up sufficient shooting space (Ortega and Gómez, 2009).

Sequences Ms4, Ms5, Ms6, Ms7, Ms8, and Ms9 were observed in both ACB and U16. In all cases, the ball remained in the outer area, from where the shot was taken. This area was associated with a significantly higher number of unfavorable outcomes in U16 compared with ACB. The sequences included short passes between adjacent areas, making it less likely to destabilize the defense (Fewell et al., 2012; Ortega and Gómez, 2009). These technical-tactical situations were not successful in either category, even though some of the sequences contained actions associated with more favorable outcomes, such as a last left-to-right pass to destabilize the defense in Ms6 and distribution of the ball from the central area in Ms4 and Ms7 (Refoyo et al., 2009). Sequences Ms8 and Ms9, by contrast, included technical-tactical situations associated with lower likelihood of success, such as use of the central areas (CO and EO) for the last action (Refoyo et al., 2009) and passes made in the same area as from where the shot was taken (outer area of the right side of the court) (Fewel et al., 2012).

In conclusion, within an observational methodology framework, we used an adaptation of the SOBL-2 observation instrument (Fernández et al., 2009) to analyze successful and unsuccessful offensive sequences in professional and elite U16 basketball. We detected similarities and differences in how players built efficient and inefficient attacks and owing to our synchronic analysis of frequency counts we were able to contextualize the results of the diachronic $\mathrm{T}$ pattern analysis performed using Theme software (Magnusson, 1996, 2000).

Apart from its methodological interest, our study also provides practical results of interest to basketball coaches. Those training toplevel U16 players, for example, should work on narrowing the gap detected between these younger teams and teams competing in the $\mathrm{ACB}$ in terms of static attacks and outside shots. Our characterization of successful and unsuccessful offensive sequences also provides useful information for designing training drills aimed at optimizing performance. Coaches of both categories should focus on exercises aimed at improving movement of the ball to create space between passers and receivers. Sample drills would involve passing the ball around the outside of the zone to culminate in a pass to the paint rather than a shot from the same position or area as the last pass. U16 coaches should also train players to make simultaneous use of the central area and the paint rather than the central and intermediate areas for the last pass and shot. 


\section{Acknowledgements}

We gratefully acknowledge the support of both Spanish government projects: La actividad fisica y el deporte como potenciadores del estilo de vida saludable: Evaluación del comportamiento deportivo desde metodologías no intrusivas (Secretaría de Estado de Investigación, Desarrollo e Innovación del Ministerio de Economía y Competitividad) during the period 2016-2018 [Grant DEP2015-66069-P (MINECO/FEDER, UE)], and Avances metodológicos y tecnológicos en el estudio observacional del comportamiento deportivo (Secretaría de Estado de Investigación, Desarrollo e Innovación del Ministerio de Economía y Competitividad) during the period 2015-2017 [Grant PSI2015-71947-REDT]. This study was also funded by grants from the University of La Rioja, and, lastly, we gratefully acknowledge the support of the Generalitat de Catalunya, research group Grup de Recerca I Innovació en Dissenys (GRID). Tecnologia $i$ aplicació multimedia $i$ digital als dissenys observacionals [Grant number 2014 SGR 971].

\section{References}

Anguera MT. Observational Typology. Qual Quant, 1979; 13(6): 449-484

Anguera MT, Blanco-Villaseñor A, Hernández-Mendo A, Losada JL. Observational designs: their suitability and application in sportsPsychology. Cuadernos Psicol Deporte, 2011; 11(2): 63-76

Amatria M, Lapresa D, Arana J, Anguera MT, Garzón B. Optimization of Game Formats in U10 Soccer Using Logistic Regression Analysis. J Hum Kinet, 2016; 54, 201-201

Bakeman R. Untangling streams of behavior: Sequential analysis of observation data. In G. P. Sackett (Ed.), Observing Behavior, Vol. 2: Data collection and analysis methods (pp. 63-78). Baltimore: University of Park Press; 1978

Bakeman R, Quera V. Using SDIS with GSEQ. Metodología de las Ciencias del Comportamiento, 2001; 3(2): 195214

Bourbousson J, Sève C, McGarry T. Space-time coordination dynamics in basketball: Part 2. The interaction between the two teams. J Sport Sci, 2010; 28(3): 349-58

Castellano J, Perea A, Alday L, Hernandez-Mendo A. The Measuring and Observation Tool in Sports. Beh Res Meth, 2008; 40(3): 898-905

Cohen J. Weighted Kappa: nominal scale agreement with provision for scaled disagreement or partial credit. Psychol Bull, 1968; 70: 213-220

Courel J, Suárez E, Ortega E, Piñar MI, Cárdenas D. Is the inside pass a performance indicator? Observational analysis of elite basketball teams. Rev Psicol Deporte, 2013; 22(1): 191-194

Cronbach LJ, Gleser GC, Nanda H, Rajaratnam N. The dependability of behavioral measurements: theory of generalizability for scores and profiles. New York: Wiley; 1972

Fernández J, Camerino O, Anguera MT, Jonsson GK. Identifying and analyzing the construction and effectiveness of offensive plays in basketball by using sistematic observation. Beh Res Meth, 2009; 41(3): 719-730

Fewell JH, Armbruster D, Ingraham J, Petersen A, Waters JS. Basketball Teams as Strategic Networks. PLoS ONE, 2012; 7(11): https://doi.org/10.1371/journal.pone.0047445

García J, Ibáñez SJ, Cañadas M, Antúnez A. Complex system theory in team sports, example in 5 on 5 basketball context. Rev Psicol Deporte, 2013a; 22(1): 209-213

García J, Ibáñez SJ, Martínez de Santos R, Leite N, Sampaio AJ. Identifying Basketball Performance Indicators in Regular season and Playoff Games. J Hum Kinet, 2013b; 36: 161-168

Garzón B, Lapresa D, Anguera MT, Arana J. Observational analysis of the free throw shot made by 
grassroots basketball players. Psicothema, 2011; 23(4): 851-857

Hernández-Mendo A, Ramos F, Pastrana JL. SAGT: Software for the application of the Generalizability Theory. 2012; Safe Creative Code: 1204191501059

Ibáñez SJ, Feu S, García J, Parejo I, Cañadas M. Shot efficacy in the NBA: A multifactorial analysis. Cultura, Ciencia y Deporte, 2009; 4(10): 39-47

Lapresa D, Alsasua R, Arana J, Anguera MT, Garzón B. Observational analysis of the construction of offensive sequences that end in a shot in youth basketball. Rev Psicol Deporte, 2014; 23(2): 365-376

Lapresa D, Anguera MT, Alsasua R, Arana J, Garzón B. Comparative analysis of T-patterns using real time data and simulated data by assignment of conventional durations: the construction of efficacy in children's basketball. Int J Perform Anal Sport, 2013; 13(2): 321-339

Lorenzo A, Gómez MA, Ortega E, Ibáñez SJ, Sampaio AJ. Game related statistics which discriminate between winning and losing under-16 male basketball games. J Sport Sci Med, 2010; 9 (4): 664-668

Magnusson MS. Hidden real-time patterns in intra- and inter-individual behavior. Eur J Psychol Assess, 1996; 12: $112-123$

Magnusson MS. Discovering hidden time patterns in behavior: T-patterns and their detection. Behavior Research Methods, Instrum Comput, 2000; 32(1): 93-110

Marmarinos C, Apostolidis N, Kostopoulos N, Apostolidis A. Efficacy of the "Pick and Roll" Offense in Top Level European Basketball Teams. J Hum Kinet, 2016; 51: 121-129

Maszczyk A, Gołaś A, Pietraszewski P, Roczniok R, Zając A, Stanula A. Application of Neural and Regression Models in Sports Results Prediction. Procedia - Soci Behavio Sci, 2014; 117: 482-487

Mexas K, Tsitskaris G, Kyriakou D, Garefis A. Comparison of effectiveness of organized offences between two different championships in high level basketball. Int J Perform Anal Sport, 2005; 5(1): 72-82

Mikolajec K, Waskiewicz Z, Maszczyk A, Bacik B, Kurek P, Zając, A. Effects of stretching and strength exercises on speed and power abilities in male basketball players. Isokinet Exerc Sci. 2012; 20(1): 61-69

Oliver RM, Camerino O. The effectiveness of the attack in basketball, example of an observational study with T-patterns. Retos, 2013; 24: 67-71

Ortega E, Gómez MA. Observational methodology in youth basketball. Murcia: Diego Marín Libreo; 2009

Ortega E, Palao JM, Gómez MA, Lorenzo A, Cárdenas D. Analysis of the efficacy of possessions in boys' 16and-under basketball teams: differences between winning and losing teams. Percept Mot Skills, 2007; 104: $961-964$

Ozakaki VH, Rodacki AL. Increased distance of shooting on basketball jump shot. J Sport Sci Med, 2012; 11: 231-237

Piñar MI, Estévez-López F, Ortega V, Conde J, Alarcón F, Cárdenas D. Characteristics of attack phases in boys' 14-and-under basketball competition. Rev Int Med Cienc Act Fís Deporte, 2014; 14 (54): 265-278

Podmenik N, Leskosek B, Erculj F. The Effect of Introducing a Smaller and Lighter Basketball on Female Basketball Players' Shot Accuracy. J Hum Kinet, 2012; 31, 131-137

Ratgeber L, Markoski B, Pecev P, Lacmanović D, Ivanković Z. Comparative Review of Statistical Parameters for Men's and Women's Basketball Leagues in Serbia. Acta Polytechnica Hungarica, 2013; 10: 6

Refoyo I, Romaris IU, Sampedro J. Analysis of men's and women's basketball fast-breaks. Rev Psicol Deporte, 2009; 18(3): 439-444

Sampaio J, Lago C, Drinkwater EJ. Explanations for the United States of America's dominance in basketball 
at the Beijing Olympic Games (2008). J Sport Sci, 2010; 28(2): 147-152

Sautu LM, Garay JO, Hernández-Mendo A. Observation and analysis of indirect interactions in ACB basketball. Cuadernos Psicol Deporte, 2009; 9(Suppl): 69

Simovic S, Matkovic B, Mijanovic M, Kocic M, Vojvodic M. Structure of efficiency factor at XIII, XIV, XV and XVI World Championship in basketball. J Human Sport Exerc, 2012; 7(2), 527-543

Strumbelj E, Vracar P, Robnik-Sikonja M, Dezman B, Erculj F. A Decade of Euroleague Basketball: an Analysis of Trends and Recent Rule change Effects. J Hum Kinet, 2013; 38, 183-189

Uchida Y, Mizuguchi N, Honda M, Kanosue K. Prediction of shot success for basketball free throws: visual search strategy. Eur J Sport Sci, 2014; 14(5): 426-432

\section{Corresponding author:}

\section{Daniel Lapresa, PhD}

Department of Educational Sciences / University of La Rioja.

Edificio Vives. C/ Luis de Ulloa s/n.

26004. Logroño. La Rioja - Spain

Phone: +34 941299282

E-Mail: daniel.lapresa@unirioja.es 